\title{
AMBIGÜEDAD DE LA PALABRA "PÚBLICO" EN EL SIGLO XVIII
}

En 1832, y bajo el seudónimo de "El Pobrecito Hablador", Mariano José de Larra comienza su primer artículo comentando que una vez decidido a escribir para el público, tiene que averiguar de antemano "quién es el público". Aunque la proposición tenga un aire razonable, parece como si hubiera expuesto una cuestión ilógica. Dijérase que utilizó la palabra clave de su premisa y conclusión con diferentes valores, pues en cierto modo únicamente podía preguntarse qué era el público, y no quién.

El vocablo alude a todos los habitantes de una región o lugar, a la población considerada en conjunto. Interpretación que se acomoda a la definición del Diccionario de Autoridades de 1737, y que repiten luego las sucesivas ediciones hasta la décima de 1852: "se toma por el común del pueblo o ciudad" 1. Escribiendo, pues, "para el público", podemos ver a Larra en el papel harto definido de quien intenta ilustrar a toda la comunidad, de benefactor de la res publica. Sin embargo, cuando trata de identificar "quién es el público", ya no se refiere a la totalidad como unidad integrante, sino a las partes que la componen. Este ligero cambio de sentido? anticipa por fuerza el desarrollo de la nueva definición que la Real Academia ofrece de público en la undécima edición del Diccionario (1869): "Conjunto de las personas que participan de unas mismas aficiones o con preferencia concurren a determinado lugar. Cada escritor, cada teatro tiene su publico". Antes de hablar de "un" público o de "su" público ${ }^{3}$, hay que abandonar la concepción abs-

1 Se ha modernizado la ortografía y puntuación de todos los textos españoles que se citan.-La traducción se debe a don Felipe C. R. Maldonado, a quien deseo expresar mi gratitud.

2 Me atengo a la distinción que sienta el Oxford English dictionary: "b) The community as an agregate, but not in its organized capacity; hence the members of the community". Se apoya en textos de Boyle (1665), Steele (I7II) y otros autores.

3 El uso del sustantivo para denominar a los espectadores de una función teatral está documentado en 1784 , en un texto que acusa la presencia 
tracta de una población total, para interpretar el término como alusivo a los miembros de la comunidad. Larra destacó de manera maestra la confusión entre ambos significados, para demostrar cuán vacío estaba el concepto "público" de un valor normativo para el escritor que acomete con la mayor seriedad su función artística. La palabra representa cualquier cosa menos un cuerpo aglutinado. Cada uno de los sucesivos grupitos con que tropezaba en su paseo por Madrid, le demostraba un gusto antojadizo y variable, aunque afectado de una constante inmutable: cierta predilección insensata por lo que fuera inferior y defectuoso.

A buen seguro que Larra se sintió ganado por la desilusión. Lo podemos ver en un pasaje comparativo tocante a "público", en el que se advierte hasta qué punto hubiera deseado que fuera el mundo de otra forma. El breve "Tratado de sinónimos de la lengua castellana" es meridiano sobre su opinión acerca de las diferencias que acusan las tres palabras clave, pueblo, público y vulgo:

Del pueblo se habla con miedo; del público con respeto; del vulgo con desprecio. El pueblo es temible, el público respetable porque representa la reunión de lo escogido de las gentes sensatas, al paso que aquél representa la fuerza de una nación entera. El vulgo es la hez de la sociedad. Al pueblo es preciso engañarle con maña, sujetarle con fuerza o sucumbir. Al público basta con deslumhrarle. El vulgo tiene todas las ideas equivocadas, se le dirige con milagros con las más groseras patrañas por poca apariencia que tengan de verdad: es la masa común de las gentes que no se distinguen ni se hacen en nada visibles ${ }^{4}$.

De acuerdo con este pasaje, "El Pobrecito Hablador", cuando trata de ilustrar al público, no se dirige a la vasta comunidad que define la Real Academia, sino a un escogido auditorio. El "público" que aquí describe nos recuerda la tradicional antinomia de discre-

de ambos artículos, determinado e indeterminado: “... reflexionando el Gobierno que los teatros en las funciones de diversión es el lugar donde más requiere la tranquilidad y decencia, para que el tiempo de su asistencia surta el efecto de entretenimiento que se busca por todas clases, las que juntas forman el cuerpo del público considerado allí unido, y acreedor al recíproco mayor respeto...; se manda que se guarde y observe con el más exacto cumplimiento lo prevenido en los artículos siguientes: ... que todos los parajes son abrigados; y que si no le acomodase así a alguno, puede escusar la concurrencia, buscando sus comodidades sin agravio de tercero, y sin disturbar la atención que un público se merece..." (Memorial literario, instructivo y curioso de la corte de Madrid, marzo de 1784, pp. 108-109).-Agradezco profundamente al profesor don Rafael Lapesa su amabilidad al dejarme consultar la documentación sobre príblico, que se guarda en el "Seminario lexicográfico" de la Real Academia Española.

${ }_{4} B A E$, t. 129, p. 219. El artículo "¿Quién es el público y dónde se en. cuentra?", se puede ver en el t. 127, pp. 73-77 de la misma edición. 
tos y necios o vulgo, por cuanto "lo escogido de las gentes sensatas" equivale a unos pocos y no a la masa, es algo respetable y no vil, capaz de asimilar la verdad antes que de seguir ciegamente una opinión tumultuaria. Con todo, ateniéndose a la definición académica o a la suya, Larra se acerca a la decepción. De hecho, como refiere en su artículo, el público es tan arbitrario y proclive a las "ideas equivocadas", que prácticamente desaparece la línea divisoria entre los conceptos opuestos.

Podría decirse que la ambigüedad que acabamos de observar es el tercer paso en la historia de público: los dos primeros determinan el cambio desde considerarlo unidad colectiva a juzgarlo un compuesto de diferentes sectores; acto seguido surge la naturaleza equívoca o decepcionante de los individuos que integran el conjunto. Entenderemos mejor cómo se produce la evolución en el siglo anterior a Larra, si ponemos mayor atención en "pueblo", el otro sinónimo de su análisis, sobre todo porque el Diccionario de Autoridades lo usa para definir público. Larra llamó pueblo a "la nación entera", lo que presupone un organismo de mayor categoría política que el meramente colectivo descrito por la Real Academia en 1737: "Pueblo: s.m. El lugar o ciudad que está poblado de gente. Lat. oppidum... Pueblo tanto quiere decir como ayuntamiento de gentes de todas maneras, de aquella tierra do se llegan... Se toma también por el conjunto de gentes que habita el lugar. Lat. populus... Se llama también la gente común y ordinaria de alguna ciudad o población, a distinción de los nobles. Lat. plebs, vulgus..."

Las acepciones de pueblo apuntan a lo que será un patrón básico para el desarrollo de público, desde el instante en que la totalidad de la población ("populus") recibe igual nombre que una de las partes, su sector más humilde ("plebs, vulgus"). Cualquiera de ambos términos puede provocar en el escritor tanto sentimiento idealista cuanto condescendencia o su desdén. Todavía más, un fenómeno similar de contaminación entre colectividad y plebe, estimación y desprecio, se puede advertir en otra palabra importante, alineándola con la definición académica de público. Se trata de común, registrada con estos valores en el primer diccionario (1729): "Lo que no siendo privativamente de ninguno pertenece a muchos... Vale también lo que es corriente, y está recibido y admitido de todos, y por tal reputado en la estimación del pueblo... Vale también vulgar, o de poca estimación... Usado como substantivo se llama así al pueblo todo de cualquier provincia, ciudad, villa o lugar".

En el vocabulario equivalente del siglo xvn - “ los discretos", "el vulgo", "los doctos", "el lector perverso (amado, benigno)"- 
el valor estimativo quedaba establecido como regia general. Al igual que los otros dos términos de análogo cariz semántico, sin embargo, público acusó un natural equívoco a comienzos del siglo xvin; esto requirió con el tiempo que el autor pusiera en claro su actitud ante la propia obra y ante los destinatarios previstos. Sin lugar a dudas, el creciente número de posibles lectores $\mathrm{y}$, por supuesto, la esperanza de aumentar los ingresos con nuevos clientes, más el deseo de muchos escritores de cultivar un extenso auditorio nacional, fueron los móviles que les llevaron a dirigirse al "público" 5. Tiene importancia un estudio de la terminología relevante, porque ilumina las dificultades con que tropezaron los autores al enfrentar una mayor audiencia.

Cuando el padre Benito Jerónimo Feijoo escribe su Teatro critico universal, partiendo de un ataque al crédito que merece la sabiduría popular, está bien preparado para sostener las diferencias ideológicas de sus lectores, pero no las de la crítica lingüística. Su ensayo inicial "Voz del pueblo" comienza con la célebre afirmación de que por ser la plebe superior en número pero inferior en intelecto, la voz del pueblo es inadmisible como dechado de verdad. No se puede afirmar, sin embargo, que los párrafos siguientes mantengan una precisa distinción entre la mayoría y el todo. El uso que hace Feijoo de vulgo y pueblo delata una identidad de valor y asimismo que las opiniones mantenidas por ambos están muy cerca de las expresadas por "la voz común" ". Sus ene-

5 Sobre su desarrollo en Francia he consultado Erich Auerbach, "La cour et la ville", Scenes from the drama of European literature, New York, 1959, pp. 133-79; y el artículo (ampliamente basado en el Abbé Jean-Baptiste DuBos), de RÉmy G. SaIsselin, The rule of reason and the ruses of the heart. A philosophical dictionary..., Case-Western Reserve Univ. Press, 1970, pp. 171-76. Son provechosos para el estudio de la situación en Inglaterra A. S. Collins, "The growth of the reading public during the eighteenth century", RES, 2 (1926) . 284-294, 428-438, y Alexandre Beljame, Men of letters and the English public in the eighteenth century 1660-1774, tr. E. O. Lorimer, London, 1948. En cuanto a España, véase la relevante tesis de Paul-Jacques Guinard, La presse espagnole de 1737 à 1791, Paris, 1973, pp. 69-89; y las comunicaciones publicadas en Creación y público en la literatura española, ed. de J. F. Botrel y S. Salaün, Madrid 1974; uno de los ponentes, Jean Sentaurens, alude brevemente al problema de la palabra público en pp. 74-75, nota 27.

6 "Preguntado alguna vez el Papa Juan XXIII qué cosa era la que distaba más de la verdad, respondió que el dictamen del vulgo. Tan persuadido estaba a lo mismo el severísimo Foción, que, orando una vez en Atenas, como viese que todo el pueblo de común consentimiento levantaba la voz en su aplauso, preguntó a los amigos que tenía cerca de sí que en qué había errado, pareciéndole que en la ceguera del pueblo no cabía aplaudir sino los desaciertos... Los que dan tanta autoridad a la voz común no prevén una peligrosa consecuencia que está muy vecina a su dictamen... El vulgo de los hombres, como la ínfima y más humilde porción de la orbe, se parece al elemento de la tierra en cuyos senos se produce poco oro, pero muchísimo hierro" (Teatro critico 
migos captaron en seguida la imprecisión aparente de aquella terminología. Salvador José Mañer, tan insufrible de costumbre por sus razonamientos superficiales y su mezquindad, tiene mayor atractivo cuando hace reproches a Feijoo por haber confundido "la voz del pueblo" con "la voz común". Aquélla "procede y se considera en el pueblo, que se compone de nobleza y plebe, de eclesiástico y secular, en que entran todas jerarquías, y así no puede tenerse por una propia la voz común..." ‘. Afirma que con propiedad se tiene a la última por expresión de una muchedumbre vulgar, en tanto que "la voz del pueblo... se organiza en la misma plebe unida con las demás partes que componen una república". Por consiguiente, se puede aceptar la autoridad de la vox populi.

No aceptó Feijoo sino una parte del desafío a su tesis. Tras algunos reparos a Mañer por arrogarse autoridad en materia de usanzas, soslaya la defensa que hace su oponente de la voz del pueblo, y se reduce a defender cáusticamente el empleo del segundo término:

La expresión voz común a cada paso se usa para significar del todo de la República, sin excepción de clases. Y así, si uno dice, "Entre los españoles es voz común que el cuerpo de Santiago está en Galicia", nadie entiende que se atribuye este sentir sólo a la plebe de España. Ya entiendo de donde vino la equivocación del señor Mañer. Vio que la expresión estado común significa el villanaje, y por aquí quiso regular la expresión voz común, sin advertir que el adjetivo común (como otros muchos) significa con más o menos limitación según el substantivo a que se aplica. Pregúnteles a los lógicos si por razón común entienden sólo los predicados que convienen a los entes vulgares; y a los políticos si por utilidad común entienden únicamente el interés de los plebeyos ${ }^{8}$.

Feijoo demostró su admirable habilidad para sofisticar una cuestión filológica, pero no consiguió enterrar la polémica, pues volvió a la carga el padre Francisco Soto y Marne. No hay por qué repetir sus argumentos, que abundan en los de Mañer, a excepción de un curioso detalle. Si aquél identificaba la voz común con la de la plebe, Soto y Marne la relaciona con un rango más amplio y lumi-

universal, Madrid, 1726, t. 1, pp. 2-3). Los dos volúmenes siguientes, que se citan más adelante, fueron impresos en Madrid por Francisco del Hierro en 1728 y 1729 respectivamente.

7 Anti-teatro critico sobre el primero y segundo tomo del teatro critico universal, Madrid, 1729, p. 1.

8 Ilustración apologética al primer y segundo tomo del teatro critico, Мadrid, 1729, p. 1. Tampoco sirve en el asunto un aliado de Feijoo, fray Martín Sarmiento; de hecho, tan sólo se apoyará en los principios de su maestro; Demostración crítico-apologética del teatro critico universal, 1732, t. 1, p. 6 (4a ed., Madrid, 1757). 
noso de pueblo: "P. Mro.: la yoz común siempre se ha merecido el aprecio y asenso de los verdaderos críticos porque comprehende la brillante clase de los doctos, cuyo circunspecto juicio examina, pesa y gradúa la cualidad del concepto. En esta prudente circunspección se funda aquella máxima de Vox populi, vox de ${ }^{9}$ ". En suma, el puñado de textos que hemos repasado nos informa que "pueblo" y "común" comparten una cierta ambigüedad en cuanto a que vayan referidos a una comunidad general y variada, o a un sector de la misma inculto y torpe.

Resulta igualmente ilustrativa en otro aspecto la polémica entre Feijoo y estos dos adversarios, pues despierta nuestro interés por un equívoco análogo en la palabra vulgo. Parecía estar convenido que la identificación de una persona con el vulgo no residía en su condición social sino en su discernimiento. Pone de manifiesto tal inteligencia en el siglo xvn la expresión de un autor de la nobleza, Francisco Gutiérrez de los Ríos, tercer conde de Fernán Núñez: "No componen el vulgo solamente los plebeyos y gente ordinaria, porque vulgo son todos aquellos que, ignorantes de las cosas humanas y presumidos como los más hombres lo son, juzgan y hablan de ellas imprudentemente y resueltamente 10". Además, otra corriente del pensamiento -Mal Lara, González de Salas e incluso Cervantes- juzgaba capaz al vulgo de una sabiduría casera, de una cierta perspicacia y aun de buen tino, por lo que su reacción, sobre todo en el teatro, merecía de parte de los autores una respetuosa expectación. Este punto de vista, sin embargo, no ejerció la misma influencia que el anterior.

Lo que parece nuevo, a mi entender, es la dificultad que los escritores del siglo xvin experimentan en sentar unas líneas divisorias incuestionables. Si uno llama vulgar a otro, imaginándose superior, es para saber a la postre que le merece igual concepto despectivo. La confianza de Mañer en su autoestimación recibirá

9 Reflexiones crítico-apologéticas sobre las obras del Rr. P. Maestro Benito Jerónimo Feijoo, Salamanca, 1749, t. 1. pp. 66-67.

10 El hombre práctico, 1680 [Madrid, 1764]. pp. 426-427. Juan de Valdés, Cervantes y Gracián, por ejemplo, habían expuesto ya ese punto de vista, aunque un escritor tardío del siglo xvn, José Alcázar, sea quien identifique con mayor precisión el vulgo y la capa inferior de la sociedad. Véanse los dos artículos siguientes de Otis $\mathbf{H}$. Green, "On the attitude toward the vulgo in the Spanish Siglo de Oro", StR, 4 (1957), 190-200; y " "Se acicalaron los audi. torios»: An aspect of the Spanish literary baroque", $H R, 27$ (1959), 413-422; E. C. RiLey, "Author and public", Cervantes" theory of the novel, Oxford, 1962, pp. 107.115; A. Porqueras Mayo y F. Sánchez Escribano, "Función del vulgo en la preceptiva dramática de la Edad de Oro", $R F E, 50$ (1967), 123 143, y Alberto Porqueras Mayo, El prólogo en el manierismo y barroco espa. ñoles, Madrid, 1968, pp. 17-19. 
las burlas de Feijoo en otro pasaje de la Ilustración apologética, del que salen a un tiempo apabullados teorías y teorizante:

... asienta que erré en atribuir solamente al vulgo la nimia confianza en la medicina; y lo prueba porque muchos fuera del vulgo están impresionados de esa nimia confianza. Este argumento se funda en el errado concepto de que sólo es vulgo el que viste gabán y polainas. Señor Mañer, para el efecto que aquí se trata, hay algún vulgo metido de gorra entre las pelucas, entre las togas, entre los bonetes, entre las capillas. Y para decirlo de una vez, ni aun se escapan de ser vulgo algunos de los que se precian de escritores, y muchos de los que se meten a Tertulios (p. 23) ${ }^{11}$.

Un amigo de Mañer, por su parte, no vaciló en juzgar que Feijoo sólo sería apreciado por el vulgo, a pesar de la evidente dificultad que oponían las confesadas intenciones del benedictino de atacar los errores en que caen sus componentes. Afirma el contradictor que la masa popular, predispuesta contra los seglares y en favor de los religiosos, despreciará el Anti-teatro critico, libro que sólo busca el aplauso de los discretos ${ }^{12}$. Con el mayor desenfado, Feijoo le replicó que habiéndose metido a desengañar al público de sus falsas opiniones, debía combatir a Mañer, el cual "como si fuese juez conservador de los errores del vulgo, solicitó mantenerlos en su anticuada posesión" (Ilustración, p. s. n.). Más adelante, Soto y Marne se declara convencido de que el Teatro crítico logrará una aceptación sin distingos, porque "los necios" se sienten habitualmente atraídos por el brillo de una enseñanza superficial (Reflexiones, t. 1, p. 21). Algunas páginas más adelante reconoce que Feijoo es tan inteligente, "que tiene equivocados no sólo a

11 De la última puntada que tira Feijoo se deduce que Mañer es el responsable del ataque contenido en la Tertulia histórica y apologética (s. 1. n. a.), publicado a nombre de "Don Jaime Ardanaz y Centellas". La idea general de Feijoo aparece de nuevo al final de una novela de Domingo Ugrna: "Vulgo: Palabra equívoca que comprende todas las órdenes de la sociedad; entran en él señores de mucha distinción. muchísima peluca y muchísimo espadín" ("Diccionario parafrástico para entender mejor la novela", Entusiasmo alegórico, Madrid, 1788, p. cxviii) .

12 "Al vulgo, contra quien dirigió su teatro el Padre Maestro, le contemplo enemigo del anti-teatro, pues le veo parcial de sus doctrinas (efecto regular de las novedades), pero como debe usted sólo apetecer la aceptación de los discretos, vocee el vulgo lo que quisiere... [El] intento sólo de oponerse usted al Reverendísimo Feijoo tan mano a mano, acredita su ánimo de gallardo; y más cuando a sujetos de corbata los contempla el vulgo incapaces de saber lo que los religiosos, como si fuesen las facultades inseparables de los claustros, y el estado secular repugnase el incomparable beneficio de la sabiduria" ("Carta de don Gaspar Domingo de Angós... al autor", Anti-teatro critico, p. s. n.). 
los ignorantes preciados de curiosos, si también a muchos inteligentes tenidos por eruditos" (t. 1, p. 25) ${ }^{13}$.

Los inteligentes quedan embaucados como los ignorantes, apilados los eruditos con los estúpidos, y los enemigos intercambian acusaciones de solicitar o halagar a la necia multitud. En esta confusión de categorías intelectuales, sin embargo, alguien más entra en combate defendiendo a Feijoo en un tratado anónimo contra el autor de ciertas notas críticas, de quien dice: "Prueba con un silogismo ser inútil [el "Consectario contra los filósofos modernos"] porque no es materia para el vulgo; pero es necesario entender el Anotador que hay vulgo de discretos y doctos y vulgo de mentecatos, y si no fuere para desterrar errores comunes de éstos, servirá para los otros" 14. Con el hallazgo de un "vulgo de discretos" el pisto es absoluto.

Aunque los críticos vituperasen la pretendida vanagloria y ánimo interesado de Feijoo, él manifestó con frecuencia que tan sólo escribía en bien del público. No obstante, el empleo específico que hace de la palabra publico ${ }^{15}$ dista mucho de ser uniforme, y un examen de los respectivos alcances acusa las dos vertientes a que ya hemos aludido. Las diferencias no son siempre acusadas y cabe contar con alguna superposición de valores. Hay que consignar el uso del vocablo como equivalente virtual de "patria", con referencia indudable a la totalidad de la población considerada como un todo orgánico:

13 Soto y Marne se valió de una imagen más picante para simbolizar los ataques de su adversario contra los errores comunes y la crítica culta: "V. Rma. debe de haber ganado algún privilegio de los dioses para transferir a las representaciones de su teatro aquella mágica actividad que animaba las famosas transformaciones del fabuloso Proteo: pues ya se representa V. Rma. Orfeo que convierte en racionales los brutos; ya aparece Circe que transforma en brutos los racionales" (Reflexiones, t. 1, p. 47).

14 Dialogo entre el Juicio y el Desengaño (s. 1., 1727), p. 24. El autor responde a cierto Domingo Pargas Zuendía y Gosán, Anotaciones al teatro critico universal, Madrid, 1727.

15 En el siglo anterior el sustantivo fue mucho menos empleado que el adjetivo. Sebastián de Covarrubias registra "publicar", "publicidad", y el adjetivo, pero no el nombre (Tesoro de la lengua castellana o española, Madrid, 1611). CÉsar Oudin glosa varias formas de la palabra, pero no incluye el sustantivo (Tesoro de las dos lenguas francesa y española, Paris, 1616). Francisco Sobrino traduce "El público" castellano al equivalente francés, pero aclara "Le public" como "tout le peuple en général" (Diccionario nuevo de las lenguas española y francesa, Bruselas, 1705). Jorn Stevens omite el nombre, aunque anota en el adjetivo, "the Public weale, Republica" ( $A$ new Spanish and English dictionary, London, 1706). Cf. P. Esteban de Terreros y Pando, cuya definición dice años más tarde: "opuesto al particular, el común de todo el pueblo en general, la sociedad civil, los hombres, ciudadanos, etc." (Dicciona. rio castellano con las voces... correspondientes en las tres lenguas, Madrid, 1788) . 
1) ... porque se interesa mucho el público en que se coloquen en los empleos hombres bien intencionados ("La política más fina", t. 1, p. 81).

2) Aun aquellas proezas que inmortalizó la fama como últimos esfuerzos del celo por el público, acaso fueron más hijas de la ambición de gloria que del amor de la patria ("Amor de la patria y pasión nacional", t. 3, p. 213).

Pero no se refiere a la nación o al país cuando en el "Prólogo al lector", que inicia el primer tomo de su Teatro critico universal, escribe:

3) Dijo bien el padre Malebranche que aquellos autores que escriben para desterrar preocupaciones comunes no deben poner en duda en que recibirá el público con desagrado sus libros (p. s. n.).

Aquí utiliza público Feijoo como cifra de la generalidad humana hostil a cualquier crítica que le concierna; con todo, se refiere a una colectividad menos fijada que el pueblo a que aludía en los dos primeros ejemplos. Cuando reaparece la palabra en el prólogo puesto al segundo tomo, parece que se hubiera reducido su alcance para comprender únicamente a "mis lectores en general":

4) El público me ha favorecido liberalísimamente, y esto basta para que yo, bien lejos de desistir de lo empezado, continúe más fervorosamente en servir a su diversión y utilidad. Algunos quisieron con sus censuras detener la corriente de la general aceptación que logró el primer tomo... (t. 2, p. s. n.).

También sugieren los escritos de Feijoo los sutiles caminos por los cuales público adquiere un matiz peyorativo apuntando a la masa del vulgo. En el párrafo inmediato aclara y explica una expresión colectiva relacionada con "el común":

5) $\mathrm{Ni}$ debajo del nombre de errores comunes quiero significar que los que impugno sean trascendentes a todos los hombres. Bástame para darles ese nombre que estén admitidos en el común del vulgo, o tengan entre los literatos más que ordinario séquito.

El autor reduce la universalidad de "comunes" de manera que abrace solamente dos grupos, el "vulgo" y un sector de "los literatos", que no son opuestos en esta ocasión. En el pasaje inmediato se justifica por el empleo del castellano, y comenta:

No niego que hay verdades que deben ocultarse al vulgo, cuya flaqueza más peligra tal vez en la noticia que en la ignorancia, pero ésas ni en latín deben salir al público, pues harto vulgo hay entre los que entienden este idioma, y fácilmente pasan de éstos a los que no saben más que el castellano ("Prólogo", t. 1, p. s. n.). 
Desde luego, la expresión "salir al público" y la inmediata, pocas líneas más adelante, "comunicar al público", significan hacer a todos partícipes de algo en vez de limitarlo a un grupo reducido, y su intención es neutra. Pero ambos pasajes representan el riesgo de difundir sin cortapisas lo que no han de comprender los ignorantes ni los medianamente instruidos.

Para Diego de Torres Villarroel, joven contemporáneo de Feijoo, el público era inequívocamente plebeyo. $\mathrm{Y}$ de entre todos los escritores de aquellas fechas acaso sea el único que estuviera en buenos términos con ese público, lo que no deja de ser significativo. A veces asumió el papel de abogado suyo, como en este párrafo dicho ante una real sociedad médica: "El público (Señores míos) es la primera y más desnuda comunidad del mundo: es el pobre, el ignorante, el enfermo y el desvalido más visible y más acreedor a nuestras contribuciones, bienes, documentos y fatigas..."16. En otra suplicación, cuatro años más tarde, aparece la palabra dos veces, y en ambas ocasiones queda identificada con la gente menesterosa. En el primer caso es claramente definitoria ("el público, dividido en los dos gremios de la plebe y de la escuela"), por lo que muy bien puede identificarse con la fórmula tradicional para expresar las necesidades de todos los súbditos. Pero acto seguido se reduce su alcance a solamente "los pobres", al agregar la "ciudad" como entidad distinta y aislar también el cuerpo de los profesores. Se trata de una alocución ante el Real Consejo de Castilla, en la que Torres solicita mejoras en el abasto de la ciudad:

El claustro de doctores de Salamanca es cierto que me votó esta comisión; pero los que me han conducido a empujones hasta los pies de V. A. son los pobres, es el público, dividido en los dos gremios de la plebe y de la escuela. La Universidad por sí sola sin duda alguna hubiera elegido otro hombre más digno... pero los gritos y las raras aprensiones de este vulgo la persuadieron que tal vez convendría más poner sus ruegos inocentes y sus súplicas en la boca de un filósofo humilde... Suplico a V. A. que así lo haga, y que lo haga por Dios, por los pobres y por mí... Y si esto no es posible, yo juro besar por justas las deliberaciones de $\mathrm{V}$. A. aunque sean contrarias a nuestros deseos. Y el público, que recurra al cielo por sus socorros; la ciudad, que tenga paciencia; y los de mi claustro, que busquen en Dios y en su filosofía sus conformidades y consuelos ${ }^{17}$.

16 "A los señores socios de la Real Junta Práctica-médica de Ntra. Sra. de la Esperanza de Madrid (1752)", Obras, t. 5, Madrid, 1794, pp. 364-365.

17 "Segunda oración (1756)", Vida, en Obras, t. 15, 1799, pp. 273-375. La posible correlación entre público y pueblo, en el sentido de gente indocta o no universitaria, queda sugerido por la observación de Torres a su regreso a 
Lejos de condescender a tan humilde auditorio, Torres lo cultiva como escritor, y a menudo confiesa sin empacho que va en busca de su dinero. Dan fe docenas de folletos, por lo común en forma de almanaques. Un plieguecillo suelto, generosamente titulado Utilidades y divertimientos del priblico (Salamanca, 1755), empieza: "Todo es engaño... Aun este cuaderno en que abomino y descubro las cautelas y espantajos empieza desde el título a ser embuste, ganga y pasmarota. Porque cuando me puse a escribirlo no me acordaba de más utilidad ni divertimientos que los míos. Mi pura intención fue asentarme al bufete a discurrir cómo podría ganar cien ducados para ayuda de mantener otros cinco sobrinos huérfanos, párvulos, enfermos y desnudos..." (p. 5). No sólo procura Torres ganarse un posible cliente con su franqueza, sino que también desarma la solemnidad y presunción de que hacen gala quienes protestan servir al provecho y esparcimiento del público. No dirigiéndose al pueblo en general sino a las clases más bajas, Torres hace menos abstracta y gravc la palabra "público".

Tal es, en términos generales, el camino que conduce a la aparición de un ente nuevo en la escena de la literatura española, el "Señor Público" o el "Señor don Público". Lo tropiezan los ojos en la segunda mitad del siglo xvir, en el auge de los periódicos, pues la representación se aviene muy bien con el estilo llano del artículo periodístico. Más propia fuera la esperanza de que un autor consiguiese personificar inequívocamente a su público, tal y como hicieron sus predecesores con el "lector" de sus prólogos. Pero no sucede así, por cuanto la individualidad no aparece sino en el mero nombre, "Señor Público".

Francisco Mariano Nifo hizo en 1761, que yo sepa, el primer esfuerzo por resolver el problema y concretar esta entidad. Nifo era un publicista pertinaz y fuera de lo común -fundó dieciocho periódicos- y fue el primer gacetero que sólo vivió de su pluma. En las distintas páginas introductorias de aquellas publicaciones manifestó su deseo de despertar a "España", a "nuestra nación" o "patria". El procedimiento habitual fue la reimpresión de autores españoles del siglo anterior y la traducción de obras extranjeras que considera útiles. No parece que sus contemporáneos sintieran gran estima por aquellos esfuerzos; Clavijo, Romea y Tapia, Moratín y Forner, no sólo despreciaron sus gustos literarios, sino que denunciaron su primordial interés económico al aprovecharse de los viejos escritos españoles y de las descuidadas traducciones que difundía sin mayor criterio.

Salamanca: "que no era razón ni justicia que fuese paga y premio de un tan honroso beneficio que yo consegui para la Universidad y el público, un desaire tan repentino, tan impensado y tan desmerecido. Esto y más que esto habló el pueblo, y esto hablaban con él muchos doctores", ibid., pp. 277-278. 
No es difícil comprender en tal situación por qué Nifo se sintió atraído por el contraste que ofrecían el concepto académico de "público", totalidad de una población, y la multitud de opiniones que de hecho comprendía ese todo. De ahí las ideas con que principia este artículo:

Esta palabra "público" es una de las más difíciles de entender entre cuantas componen el diccionario copioso de las ideas humanas; y aunque precisa en el significado, es tan extensa en los supuestos que se deben entender por ella un sin número de caprichos, enlazados por casualidad y desunidos por naturaleza. El común de los hombres forma esta palabra, y cada uno de ellos confunde su significación. Público, a la verdad, no es otra cosa que un conjunto de pareceres, pocas veces conformes; pero pasa por un aprecio general lo que apenas es conveniencia de pocos. De esto proviene un engaño del que se dejan adular muchos que ni conocen al público ni estudian en conocerse a sí mismos. Siempre han hallado los tímidos, y los que tratados con honor se llaman discretos, un sin número de inconvenientes para hacerse bien vistos de este que llamamos Público, sujeto descontentadizo que, acaso cuando más se le sirve, se muestra menos satisfecho... ${ }^{18}$.

Nifo hizo dos observaciones originales acerca del público y de la condición de sus opiniones. Nota primero que lo que corre a título de opinión generalmente aceptada no es en realidad sino el juicio coincidente de unos pocos; parecer que, según podemos asumir, hace suyo una masa sin criterio propio. Segundo, las personas con discernimiento son tímidas y no se esfuerzan por conquistar el consenso popular. No hay una relación lógica entre ambas conclusiones, ya que Nifo no podía significar que son los discretos quienes guían a la multitud. De antemano les había tachado de retraídos, y luego insistió en la idea convencional de que "esta exquisita parte del público" está encubierta por las sombras de la ignorancia y el error (ibid., p. 99). Para comprender mejor cuáles son las ideas de Nifo debe pasarse a la presentación de las secciones inmediatas, en la que hábilmente dispone de un mantenedor y un crítico para demostrar lo que debe hacer un periodista.

Nifo pretende haber recibido una carta en la que un amigo le cuenta su confusión cuando le han invitado a escribir algo con que divertir "al señor don Público" (ibid., p. 101). Se le aconsejó que presentase una piececilla frívola si quería tener éxito, y en verdad que su propia experiencia del mal gusto que reina en España "me hizo creer que podría en pocos días hacerme uno de

18 "De la dificultad que se ofrece para contentar y dar gusto al público, porque tiene tantos paladares como individuos", Cajón de sastre o montón de muchas cosas, t. 3, núm. 18, Madrid, 1761, pp. 97-98. 
los muchos que pasan por discretos en la numerosa caterva de los tontos. Efectivamente me dejé reconvenir de esta lisonjera esperanza, dando principio a unas burlas de veras, que eran veras aunque parecían burlas" (loc. cit.). Este amigo alude con el últime comentario al sistema de mezclar o disimular el castigo con el en gaño; estrategia que apunta sin lugar a dudas al plan de Nifo. No es de menor importancia el retrato que se traza, en la carta ficticia, de una nueva categoría de escritor, que no puede identificarse con los discretos ni con los tontos. El amigo, a quien se supone hombre de alcances, trata de fingir un talento de relumbrón con que impresionar a la muchedumbre. Así pues, como "uno de los muchos que pasan por discretos", no es un mastuerzo encampanado, ya que su inteligencia es real, sino sujeto que explota con la mayor indiferencia unas dotes estimables.

En la sección inmediata el calculador amigo de Nifo refiere que cuando discutía en la tertulia sobre su aventura literaria, le reprendieron, y también al ausente $\mathrm{Nifo}$, por su insistencia en acometer materias graves. El tertuliano prefería la poesía ligera, de la que hace muestreo en las páginas siguientes. Nifo, a decir verdad, ha introducido el arduo problema de cómo un autor culto puede simultáneamente complacer a un buen número de posibles lectores y salir beneficiado; para ello se ha valido de una carta, de una composición semiboba y semigrave, del diálogo y del verso, de manera que lo útil resulte grato. Pone así en práctica la política un tanto cínica que ha desaprobado en apariencia cuando se la recomendó un amigo. Demostración que asimismo aclara cómo relaciona Nifo los dos puntos que resultaban inconexos en las observaciones preliminares. Su pensamiento básico es que los discretos pueden guiar opiniones vulgares si estudian el auditorio masivo y maquinan los medios para captar su atención.

Un texto posterior del mismo año confirma esta interpretación ${ }^{19}$. De nuevo el oportuno comentario de un "amigo" dispone la escena. Confiesa éste -y no aclara Nifo si con satisfacción o con envidia- cuánto le place observar que el publicista encuentra en el público tan a mano la fortuna que otros han de buscar en Indias. Con habilidad recoge los vocablos publico y fortuna para mostrar que ambos son fruto de la inconstancia. Como un chiquillo a quien debe mimarse y una ramera que reclama lisonjas, no son constantes sino en la ingratitud y el descontento. Alterando el virgiliano audentes Fortuna juvat, escribe Nifo: "Créame Vd. y crea que le hablo con sinceridad: al Público y a la Fortuna, para tenerlos contentos, no hay como tratarlos con desenfado..."Y afectando una completa falta de principios replica en otro lugar: "No hay más

19 "Introducción", Cajón de sastre, t. 5, 1761, p. s. n. 
Fortuna que Dios en cuanto al espíritu; y en cuanto a lo terreno, no hay Fortuna como el dinero ni mejor Público que pesos gordos". Pero no hay que tomar al pie de la letra sus expresiones de escarnio ni de codicia; son simples naipes en el juego de "engañar con la verdad", y la intención de Nifo es sugerir que un editor ingenioso puede ganarse al público mientras le instruye. No se atiene precisamente al consejo del avisado Rodrigo de Pacheco, cuyos versos utiliza para apostillar su conclusión: "Encierre ya en la cárcel de sus labios / el sabio el néctar de su fiel doctrina, / pues le han de conocer tan pocos sabios". Mixto de buscavidas y de celoso patriota, jamás se cansó de publicar buenas lecturas para sus conterráneos ${ }^{20}$.

No fue menos devoto del bien común José Clavijo y FaJardo, quien manifiesta en el prefacio a El Pensador (Madrid, 1762, p. 6) que su objeto es "mejorar a los hombres". Por ardua que sea la empresa, declara, el autor que consiga rectificar sus ideas, "les hará un servicio". Incluso en otro ensayo pone a la par su empeño y el del predicador ${ }^{21}$; y en sus observaciones preliminares diriase que sigue una fórmula evangélica de humildad y devoción cuando advierte que se daría por satisfecho con mejorar las ideas de una sola persona. Glavijo se retrata más adelante, no como un observador, antes como apasionado inquisidor de todas las clases sociales, silente y decidido, estudioso de la naturaleza humana ${ }^{22}$. El trato, sin embargo, con las gentes le exaspera en tal medida que pronto pierde su objetividad filosófica: "Todos estos, digo, y otra inmensa turba me hacen rabiar, llorar y gemir... En fin, por desgracia mía, yo soy tan sensible, especialmente en orden a aquellos

20 Atinadamente observa Luis Miguel Enciso Recio que se puede compilar una antología con las diversas actitudes que el periodista mantuvo ante el público; véase Nipho y el periodismo español del siglo xviii, Valladolid, 1956, pp. 148-149. Este mismo autor aprecia que el nivel de comunicación a que aspiraba Nifo queda establecido en la introducción a la Estafeta de Londres: "No es mi intento comunicar... asuntos tan elevados como los que aspiran a enseñar, ni tan rastreros como los que fundan todo su mérito en hacer reír" (cita en la p. 150).

21. Traza de este modo el paralelo: "aunque no su misión y facultades, el fin y objeto del Pensador es el mismo que el de un orador evangélico. La diferencia está en que el predicador directa y abiertamente acomete al vicio, tomando sus principales armas de... principios sagrados de la religión; y el autor de una sátira lícita los impugna no tan abiertamente y por otros principios no tan sagrados..." ("Pensamiento 46", El pensador, t. 4, 1763, 112 113). La comparación está citada por Guinard, op. cit., p. 188.

22 "... las horas del día que tengo libres las empleo en examinar toda clase de gentes. Tan presto me introduzco en una asamblea de políticos como en un estrado de damas. $\mathrm{Ni}$ en uno ni en otro paraje hago traición a mi querido silencio... Visito los teatros, los paseos y las tiendas; entablo mis diálogos con el sastre, el zapatero y el aguador. La Puerta del Sol me consume 
males que turban la sociedad, que no puedo mirarlos sin dolor; y tan simple, que mi filosofía pierde los estribos..." (ibid., pp. 15-16). Aumenta su zozobra, sigue diciendo, tal y "como si todos ellos fueran mis hijos, o yo tuviese comisión particular para proteger la virtud, las artes, el buen gusto y la razón" (ibid., p. 16).

No se permite Clavijo el enfoque magistral de un Feijoo, ni mantiene la retórica del predicador, el filósofo o el padre. Antes bien asume una postura de modestia y aun de indiferencia. Sus palabras adquieren un tono coloquial cuando declara: "En punto de ambición estoy muy bonitamente. Yo no me considero nacido para mandar a los hombres, ni éstos me parecen tales que merezcan la pena y afanes que cuesta el mandarlos" (loc. cit.). Crece nuestra conciencia de una postura conflictiva cuando analizamos la conclusión, pues Clavijo no se encara con un lector a quien urge la enmienda, sino con alguien entre juez y amigo colaborador:

Ya es tiempo de concluir, señor Público. Vd. está sin duda admirado de no encontrar en este prólogo zalamería ni arrogancia, pero no hay que esperar uno ni otro de mi pluma. Yo no me he de poner de rodillas a suplicar a $\mathrm{Vd}$. pase en silencio los defectos de la obra, porque antes bien estimaré me los advierta para corregirlos. Tampoco me estaría bien tratar con fanfarronadas a mis jueces. Así, si no encuentra Vd. los hipócritas epítetos de benévolo, cándido, curioso y benigno, tampoco verá los insolentes de grosero, impertinente, preocupado y necio. Váyase uno por otro; y en todo caso si a Vd. le pareciere, honrando mi trabajo, que es susceptible de crítica, que recaiga ésta sobre la obra y no sobre el operario... Basta. Seamos amigos, y crea Vd. que lo es suyo muy de veras ( $F l$ pensador, pp. 21-22).

Oscila entre crítico y amigo al encararse con sus lectores, dudando si proclamar sin tapujos su opinión acerca de todos los hombres que componen la sociedad, o si adoptar unos modales más suaves que le granjeen la simpatía de individuos tan heterogéneos.

Otro periodista de la misma época dio con la feliz solución de aparentar que en España no había gente vulgar. El abate J. Langlet dirige complacidísimo sus observaciones proemiales al "ilustre" o al "sabio y respetable público". Conforme se pasea buscando una contestación a su pregunta “¿Dónde está el vulgo?” ${ }^{23}$, encuentra las calles, teatros y librerías ocupados por ciudadanos sensibles, que responden a las ideas y a los hechos de manera loable. La evidencia de una captatio benevolentiae cerca del auditorio hispano queda subrayada por el contraste con otro pasaje ulterior, en el

algunos ratos, y en estas escuelas aprendo más en un día que pudiera en una universidad en diez años" (op. cit., pp. 13-14).

23 El hablador juicioso y crítico imparcial, Madrid, 1763, p. v. 
que Langlet previene a sus lectores contra la influencia de la necedad: "deseo conozcáis que entre los filósofos hay vulgo, y vulgo más perjudicial que el que ellos mismos abominan" ("Carta II", op. cit., pp. 3-4). La estratagema de identificar al público de modo exclusivo con "los discretos", sin embargo, pone indirectamente de manifiesto las dificultades del autor al dirigirse a un cuerpo indiferenciado de lectores.

El caso de Juan Cristóbal Romea y Tapia ofrece nuevas muestras de tal inseguridad por parte de los escritores, y ello a pesar de que al principio se muestre totalmente confiado, como quien sabe muy bien con quien habla. Se dirige al "Señor Público" calificándole agresivamente de monstruo de virtudes y vicios, engendro formado por los inteligentes y los lerdos ${ }^{24}$. Anuncia que endereza sus papeles a los sujetos más estólidos e insensibles de la sociedad. De una parte, pagan como nadie; de otra, no pueden reclamar el derecho de criticar la obra sin sacrificar los privilegios de su estupidez. El, en suma, será el único que navegue viento en popa, lejos del alcance de quien pueda ofenderle. De pronto, con tristeza, reconoce cuán imposible es todo esto, ya que en la vida cada cosa tiene un contrario que afrontar y la lucha es inevitable.

El tono de Romea cambia en el remate; su optimismo temerario cede al comprobar que los necios le juzgarán de todos modos, así como, podemos añadir, los autores envidiosos y los cínicos, que son también sus adversarios en el público. Romea se sabe independiente de dos grupos, y no precisamente de la multitud mema o ignorante. Cuando se define como "escritor sin título", se aisla de los colegas diplomados en petulancia; y el afirmar en la portada que su trabajo está "traducido del español al castellano" es una burla de los traductores incompetentes que inundan las librerías ${ }^{25}$.

24 "Señor Público: ... Vd. es un monstruo, todo virtudes y vicios, pues ya se ve que de cuantos componen su dilatado imperio, unos son necios y mentecatos, otros hábiles e instruidos. Yo, al revés de los demás, no quiero nada con éstos porque comúnmente son melancólicos y mal contentadizos; con los estólidos me las quiero avenir, que pagan mejor sus tonterías, se inclinan a lo peor, y liman sus yerros a peso de plata. Lo más que podrán decir es que mis papeles son engañabobos. Pero no sé quién, pues si lo dicen los sabios, harán muy mal porque no escribo para ellos; y los necios mucho peor, pues perderán los grandes privilegios y exenciones que la fortuna les tiene concedido ipso facto que se conozcan. Conque, ajustadas cuentas, yo seré el único que corra viento en popa, sin que haya nadie quien me ofenda en un pelo. Ya se ve que esto es pedir peras al olmo, porque todas las cosas han de tener su contrario, y no fuera tan estimada la ciencia si de cuando en cuando no carease con la ignorancia. Y así, no hay que cantar victoria sino disponerse para la pelea. Está muy bien, y yo le daré las gracias al que me convenza de mis necedades y botaratadas" (El escritor sin titulo, Madrid, 1763, pp. s. n.).

25 Estos puntos están persuasivamente expuestos por Guinard, op. cit., pp. 188-190. 
También los sandios y los cínicos escriben para doctrinar al pueblo, aunque lo perviertan en realidad. De ahí que Romea quiera diferenciar su voz de la de aquéllos, y suprimir el aura de noble dedicación en que se envuelven quienes hipócritamente claman servir al público.

La postura de Romea nos conduce casi al final del trayecto recorrido por la palabra público en el siglo xvir. Todavía pertenece al campo de las conjeturas el porqué de su empleo creciente; pero sin duda contribuyó a la difusión una clara conciencia del atraso de la cultura nacional. Cuando los autores se dirigen a esa unidad orgánica que al principio cifra el público nos parece que, con un espíritu afín al del despotismo ilustrado, quieren iluminar al pueblo español. De todas maneras, el sustantivo, desde Feijoo en adelante, demuestra, por la forma en que fue utilizado, una notable confusión con respecto a las diferentes secciones que componen la sociedad, y a la vulgar mayoría luego. Acaso tal ambigüedad sea también un reflejo de que más gente comenzó a leer, aunque defectuosamente, y a comprar publicaciones, de suerte que, cuando un autor quiso dirigirse a la comunidad en conjunto, en efecto lograba alcanzar un mayor número de lectores. El deseo de atraerse una clientela y de impresionarla, requiere una estrecha identificación entre creador y consumidor de literatura. Andando el tiempo, la acusación de vulgaridad que se lanzaba contra el público vino también a formularse contra la república literaria en general. Un escrito acusadamente crítico de finales de siglo nos proporciona un cuadro inusitado y curioso de la situación, porque aunque su autor fustiga de forma ostensible a los escritores por el bajo nivel de sus obras y defiende al público, éste no sale mejor parado:

Al juzgar por lo que se habla, se escribe y se piensa, nuestra nación debía ser la más ilustrada: las esquinas no pueden sufrir el peso de los carteles; vomitan las librerías todo género de obras; trabajan noche y día las prensas... ved la mayor parte de nuestras producciones literarias. Clámase continuamente contra el público; trátasele de juez injusto y voluble, y su paciencia es tal que después de conocer claramente la sin razón, no se queja contra los reos, y aun los elogia y enriquece. El público sufre continuos disparates, ridiculas producciones; aguanta mil extravagancias; y engañado por un título magnífico compra obras pésimas, enriquece, honra y estima a autores que no saben lo que escriben y debían aprender a leer antes de tomar la pluma en la mano; y estos mismos autores tienen la avilantez de insultarle... La caterva de escritorzuelos, que como los bárbaros del norte han hecho una irrupción en la República literaria, ... éstas son las causas de nuestro atraso ${ }^{26}$. 
En la descripción de Cecilio Pérez el "público" no se distingue del "vulgo", y los autores no son otra cosa que bárbaros tras el botín de unas liquidaciones. La corrupción general del gusto y del buen sentido es un grave impedimento para que las gentes de verdadero talento consigan audiencia; cuando menos, esto es lo que Larra quiso significar años más tarde con las equívocas palabras que puso al final de su artículo. Pretende con amargura no ser mejor que sus colegas, cuando admite que al escribir para el público, en verdad, tan sólo escribe para sí mismo.

Universidad de Michigan.

MonRoe Z. HAFTER 